\title{
IGUALDADE E CAPACIDADE CONTRIBUTIVA, LIMITAÇÕES AO PODER DE TRIBUTAR
}

\author{
Claudia Aniceto Caetano Petuba ${ }^{1}$
}

RESUMO: Em matéria de tributos a Constituição brasileira visa proteger o cidadão de eventuais abusos do Estado, ainda assim, existem alguns impostos que, devido à técnica de arrecadação utilizada, dificultam a aplicação do princípio da Igualdade às relações tributárias e acabam por estagnar uma sociedade em suas desigualdades. A capacidade contributiva é o principal critério utilizado pelo Direito Tributário para garantir a materialidade deste princípio supraconstitucional, mas não são todos os tributos que se atentam à capacidade econômica do cidadão para definir a carga tributária que poderá suportar.

Palavras-chave: Igualdade. Desigualdade. Capacidade Contributiva. Capacidade econômica. Justiça Fiscal.

\section{EQUALITY AND CONTRIBUTIVE CAPACITY, LIMITATIONS ON THE POWER TO TAX}

\begin{abstract}
In terms of taxes, the Brazilian Constitution aims to protect citizens from possible abuses by the State, however, there are some taxes that, due to the collection technique used, make it difficult to apply the principle of Equality to tax relations and end up stagnating a society in its inequalities. Contributory capacity is the main criterion used by the Tax Law to guarantee the materiality of this supraconstitutional principle, but it is not all taxes that pay attention to the economic capacity of the citizen to define the tax burden that can be borne.
\end{abstract}

Keywords: Equality. Inequality. Contributory capacity. Economic capacity. Tax justice.

\footnotetext{
${ }^{1}$ Bacharel em Direito pela FAA-IESA e em Administração pela UFAL; especialista em Direito Público pela Universidade Anhanguera e em Gestão Pública pela UFAL, mestranda em Ciências Jurídicas na Universidade Autónoma de Lisboa-UAL. Contato: claudiapetuba@gmail.com
} 


\section{INTRODUÇÃO}

Com o intuito de dirimir as desigualdades, aceitar e considerar as diferenças que desde a Antiguidade ${ }^{2}$, com Platão e Aristóteles, a palavra igualdade tem seu sentido vinculado ao da palavra justiça, quando defendiam que a igualdade consistia em tratar igualmente os iguais e desigualmente os desiguais “o injusto é o desigual, e o justo é o igual” (ARISTÓTELES, 2001).

Os séculos se passaram e a ciência jurídica se aprofundou sobre o que de fato seria a igualdade, sempre no sentido de ampliar e seguir no mesmo rumo apontado por Aristóteles. Embora sua concepção tenha se concretizado nos variados países em períodos diferenciados, hodiernamente a doutrina, sem grandes divergências, corrobora a citação acima destacada. Hans Kelsen, em sua Teoria pura do Direito, coloca que a igualdade dos indivíduos que estão sujeitos à ordem pública não significa tratá-los por forma igual nas normas legisladas com fundamento na Constituição, especialmente as leis, pois "seria absurdo impor os mesmos deveres e conferir os mesmos direitos a todos os indivíduos sem fazer quaisquer distinções” (KELSEN, 2006).

Tratando-se de desigualdade, muitas variáveis distinguem um cidadão do outro - o gênero, pigmentação da pele, faixa etária, convicções políticas e religiosas, classes sociais, dentre outras. A efetivação do direito à igualdade busca garantir o sobreprincípio da justiça. Uma linha tênue difere o que é discriminação garantida constitucionalmente (a partir da correta aplicação do princípio da igualdade) e diferenciações promovidas pelo preconceito (fato típico, antijurídico e culpável). Afinal, quais diferenças são irrelevantes e o que é relevante? A partir de qual ponto a desigualdade deve ser considerada?

O sistema constitucional não poderia desconsiderar tais fatos, pois a sociedade se organiza em notória desigualdade. O tratamento adequado aos indivíduos é o tratamento adequado a sua condição enquanto desigual, e assim deve se guiar a produção normativa, interpretação dos dispositivos legais e os entendimentos jurisprudenciais nos diversos ramos do Direito, não poderia ser diferente na seara do Direito Tributário.

A capacidade contributiva é o critério de valoração e comparação adotado pelo Direito Constitucional e Direito Tributário brasileiros para nortear o seu sistema tributário, "sem ele, não há como aplicar o mais importante e nuclear direito fundamental, ao Direito tributário: a igualdade” (BALEEIRO, 2010, p. 1100).

\footnotetext{
${ }^{2}$ Neste período, as primeiras definições de igualdade eram elaboradas do ponto de vista político, não se considerando para essa formulação as mulheres, os estrangeiros e os escravos.
} 
O objeto do presente artigo consiste na observância dos princípios da igualdade e da capacidade contributiva como limitações ao poder de tributar e garantia da justiça fiscal, compreendendo a capacidade contributiva como garantia do direito à igualdade nas relações tributárias brasileiras.

Como objetivos gerais, possui o propósito de demonstrar como o sistema tributário brasileiro pode ser justo, atentando-se às desigualdades econômicas, e demonstrar que a capacidade contributiva é o instrumento para concretizar os princípios da igualdade e justiça no Direito Tributário. De forma específica, demonstrar que a capacidade contributiva pode ser definida de acordo com a capacidade econômica do contribuinte nas diversas formas que a relação tributária se constituir; que a capacidade econômica na sua modalidade objetivaabsoluta, adotada pelo sistema tributário brasileiro, que apenas considera a renda ou patrimônio bruto, sem as devidas deduções com gastos essenciais, fere o princípio da igualdade.

Como metodologia, foi realizada a pesquisa bibliográfica sobre o tema, investigando obras, artigos e periódicos, bem como análise da legislação a respeito do sistema nacional tributária, os direitos fundamentais dos contribuintes, as limitações ao poder de tributar, a relação tributária sob as perspectivas do contribuinte e do Estado, e a formas de se obter uma tributação cidadã; com cunho descritivo e explicativo. Método dedutivo, analisando o caso particular da capacidade contributiva sob a ótica da Igualdade e Justiça.

\section{A RELAÇÃO ENTRE A IGUALDADE E A CAPACIDADE CONTRIBUTIVA}

O presente estudo parte da verificação de que o Direito é linguagem, que essa linguagem passa por um processo de interpretação e que este processo recebe influência da situação histórica em que está inserida e das concepções do intérprete. Através desse processo intelectivo da interpretação, os enunciados lingüísticos que compõem a Constituição transformam-se em normas e adquirem conteúdo normativo, incidindo sobre os interesses sociais.

Logo, os princípios da justiça, igualdade e capacidade contributiva, não seriam simplesmente aquelas palavras impressas na Constituição, mas o resultado de suas interpretações. Tais conceitos estão ligados aos valores culturais, religiosos e morais da sociedade a qual se inserem, passaram por mutações com a evolução da humanidade, o cenário atual de um mundo globalizado e multicultural fez com que tivéssemos conceitos mais 
uniformes de igualdade e justiça. Já a capacidade contributiva ainda é palco de muitas divergências.

Antes de adentramos nos conceitos e discussões sobre esses institutos, importante compreendermos o cenário em que se situa. A desigualdade material do Brasil é gritante, apenas a igualdade em sua formalidade não têm sido suficiente, os doutrinadores do constitucionalismo moderno têm aprimorado cada vez mais os caminhos para que alcance sua materialidade, os fatores de discriminação (para que não se cometam excessos ao conceder benefícios para os que já recebem tratamento igual ou ao deixar de beneficiar os que deveriam ter tratamento diferenciado), comparabilidade e a sua aplicabilidade.

A desigualdade sócio-econômica é algo que passa pelas outras formas de desigualdades - entre os sexos, étnicas, religiosas, de orientação sexual, etc. Roberto Santos em sua obra "Leis sociais e custo da mão de obra no Brasil” afirma que esses problemas de ordem econômica e social acabam por impedir que regras e princípios constitucionais sejam efetivados, “o cumprimento dos ditames constitucionais esbarra no sentimento pernicioso dos exagerados contrastes. A torpe diferença, que alimenta a alegria dos mais ricos, não está apenas na cumulação de grandes capitais” (BALEEIRO, 2010, p. 852).

A igualdade almejada é humanista, que preze pelos indivíduos e suas particularidades, embora nunca tenha se concretizado em nenhum modelo de sociedade humana - o que se tem são países mais próximos de alcançar esse patamar e outros mais distantes - , nosso país é um dos exemplos em que sua concretização, plena efetividade, encontra-se num longo período à diante da história, que poderá ser escrita com avanços ou retrocessos, num ritmo acelerado ou não.

Quanto ao princípio da igualdade, a doutrina, majoritariamente, classifica-o como um dos principais princípios do Estado Democrático de Direito adotado pela República Federativa do Brasil, diversos doutrinadores o considera o principal, é o caso de Aliomar Baleeiro: “a igualdade é o pilar básico do estado Democrático de Direito” (BALEEIRO, 2010, p. 852); e Vicente Paulo e Marcos Alexandrino: “A igualdade é a base fundamental do princípio republicano e da democracia. Tão abrangente é esse princípio que dele inúmeros outros decorrem diretamente” (ALEXANDRINO; PAULO, 2010, p.115). Para Micaela Dominguez Dutra "a igualdade é um conceito através do qual o ser humano busca alcançar a verdadeira justiça” (DUTRA, 2010, p. 21). 
A definição de igualdade carrega resquícios da luta entre as classes sociais, os critérios adotados tanto para sua limitação como para sua aplicação são baseados na comparação ou na valoração do seu mérito, o que supõe confronto, pois haverá sempre o contraste entre o igual e o desigual. Para Perelman "todo conceito concreto de igualdade é uma concepção particular do mundo e deriva para uma questão axiológica” (PERELMAN Apud BALEEIRO, 2010, p. 849). Na mesma linha segue Baleeiro, “A igualdade tomada em sentido concreto arrasta profundas divergências, pois envolve posturas ideológicas, políticas, axiológicas (BALEEIRO, 2010, p. 850).

O doutrinador Celso Antônio Bandeira de Mello é um dos que melhor explana sobre o assunto, na sua obra Conteúdo Jurídico do Princípio da Igualdade, afirmando a possibilidade de discriminações, sendo necessário, para tanto, atentar-se a alguns elementos para não se violar princípios constitucionais: as discriminações são permitidas desde que não sejam feitas considerando apenas um indivíduo, não podendo a lei utilizar elementos exterior a eles; devendo haver um nexo lógico entre o critério utilizado de discriminação e a desigualdade, e um nexo causal entre esse critério e o ordenamento jurídico, visando a proteção de ordenamentos constitucionais (MELLO, 2007, p. 21).

Segundo José Augusto Conti, para se obedecer ao princípio da igualdade, as normas devem verificar: a) a desigualdade relativa entre os indivíduos; b) a viabilidade na comparação entre os seres; e c) o critério de comparação eleito deve estar explicitado na Constituição (CONTI, 1996, p. 27). O princípio da igualdade formal é norma de tratamento que pressupõe a dessemelhança relativa, logo, faz-se necessário valorar e comparar o que é agrupado na ala dos idênticos e na dos diferentes para que se entenda o que é igualdade e consecutivamente o que é a desigualdade. Para Aliomar Baleeiro “(...) a comparabilidade e a relação proporcional estão por detrás de todas as distintas e divergentes concepções de igualdade material (e de justiça). Ninguém é feliz ou infeliz, rico ou miserável, a não ser quando comparado” (BALEEIRO, 2010, p. 852). Assim define-se a igualdade material, caso contrário teríamos apenas a igualdade formal.

Diversos são os critérios produzidos pela doutrina para comparar e definir a igualdade material, além dos citados Celso de Mello e Augusto Conti, Misabel de Abreu M. Derzi, Gerson Sicca, dentre outros, elencam critérios de comparação que, em sua maioria, não se contrariam, apenas se complementam. O cumprimento de suas orientações trazem ao ordenamento jurídico brasileiro segurança jurídica e garantem a efetividade da igualdade e da justiça. 
A justiça encontra-se positivada na maioria dos ordenamentos jurídicos modernos, Marcelo Elias Saches, objetivamente, a define "como ordenação da convivência com finalidade harmônica, estruturada em seus valores fundantes: igualdade, liberdade e fraternidade” (DUTRA, 2010, p. 18).

A capacidade contributiva está impregnada da ideia de justiça, guarda relação com o princípio da igualdade (LIMA NETO, 2005, p. 246-247), é o instrumento do sistema jurídicopositivo pelo qual se opera esses dois princípios no Direito Tributário. Conforme exposto anteriormente, a capacidade contributiva é subprincípio - assim considerada pela doutrina majoritária - da igualdade, que por sua vez deriva do sobreprincípio da justiça; e, procura, de forma específica, concretizar tais conceitos (DUTRA, 2010, p. 72). Vago o suficiente para ser enquadrado como conceito indeterminado, mas não num grau tão elevado quanto aos outros dois.

Os subprincípios da personalização ou pessoalidade, da isonomia tributária, generalidade, e capacidade contributiva (considerada proporcional ou progressivamente), complementam-se, sendo norteados por este último, são ditados pela política econômica e social do país no sentido de proibir a distinção entre os que se encontram em situação equivalente - é de extrema relevância distinguir a pessoa que figura no sujeito passivo da relação tributária.

A capacidade contributiva reproduz direito fundamental dos contribuintes, enquadra-se no conceito material de direitos fundamentais, assegurando os direitos subjetivos do cidadão contribuinte, funcionando como limite ao poder de tributar (LIMA NETO, 2005, p. 253).

Tais princípios relacionam-se com a justiça distributiva em matéria fiscal, diz respeito à repartição do ônus fiscal do modo mais justo possível, fora disso a igualdade será puramente formal. Falar em Justiça Tributária numa sociedade democrática e que tenha como um dos seus principais valores a justiça, precisamos notar a presença de pelo menos duas características básicas: I - uma forte regulação na distribuição de bens na estrutura básica da sociedade, e II cidadãos-contribuintes que em uma democracia constitucional pagam tributos e mantêm um fundo comum público, destinado a garantir a oferta de bens e de serviços impossíveis de serem assegurados com equidade a todos os cidadão, se entregues ao mercado (DUTRA, 2010, p. 2021).

Baleeiro comenta, sobre as disparidades, que quanto maiores forem os contrastes econômico-sociais na sociedade “mais se formam os sentimentos de revolta e de injustiças dos economicamente mais fracos. (...) A pobreza exacerbada de uma massa considerável de 
brasileiros limita o crescimento econômico e a riqueza da nação” (BALEEIRO, 2010, p. 852). É defensor de que tais desigualdades devem ser consideradas com o fim de restabelecer o equilíbrio social, que a esfera do Direito Tributário pode contribuir com o retomar de tal equilíbrio, como por ex. a progressividade dos tributos que "favorece a igualação das díspares condições concretas, em vez de conservá-las ou atenuá-las” (BALEEIRO, 2010, p. 859).

Sampaio Dória apontou as discriminações consideradas lícitas em matéria tributária, com sendo as baseadas em diferenças de fato entre as pessoas ou objetos tributados, as baseadas no interesse fiscal do Estado e as fundadas no interesse social (BALEEIRO, 2010, p. 1102).

\section{A CAPACIDADE CONTRIBUTIVA}

Com a evolução do conceito de igualdade, passou-se a se pregar a redução das desigualdades econômicas e a progressividade na tributação, como uma necessidade da sociedade capitalista que se fortalecia, pois a miséria afetaria o consumismo - pilar fundamental de uma sociedade capitalista -, a preparação da mão de obra especializada, o desenvolvimento e a eficácia econômica. E que uma drástica igualação reduziria o sentimento de felicidade dos ricos, que se nutrem da diferença (BALEEIRO, 2010, p. 852).

Há mais de dois séculos, preconizado pelo economista alemão VON IUSTI e difundido por ADAM SMITH, em sua obra clássica “The Welth of Nations”, afirmou-se a necessidade da contribuição para as despesas do Estado serem proporcionalmente justas (BALEEIRO, 2010, p. 1090).

Essa discussão é recente ao se comparar ao ingresso de outros institutos como objeto de estudo da Ciência do Direito. Após a Primeira Grande Guerra Mundial, a capacidade contributiva passou a figurar nos textos legais, como é o caso da Constituição de Weimar, de 14 de agosto de 1919, dividindo opiniões desde então.

Este dispositivo inovou o sistema tributário brasileiro através da Constituição de 1946 com o artigo 202 que dizia "Os tributos terão caráter pessoal sempre que isso for possível, e serão graduados conforme a capacidade econômica do contribuinte”, artigo suprimido com a edição da Emenda Constitucional de n. 18, de $1^{\circ}$ de dezembro de 1965, que introduziu a reforma tributária na Constituição de 1946, um longo silêncio sobre o referido instituto atingiu as Cartas 
de 1967 e 1969. Concordando com Regina Helena Costa, vemos a supressão da capacidade contributiva como flagrante retrocesso (COSTA, 1998, p. 101).

O instituto da capacidade contributiva foi reinserido no ordenamento jurídico brasileiro em mais um período de redemocratização. Após anos negros de repressão às liberdades e garantias individuais, a Constituição de 1988 garantiu grandes avanços sociais, possibilitando o vislumbre pelos cidadãos de uma vida menos indigna. Nos mais variados ramos do direito o ideário de igualdade é marcante.

Vista sob o ângulo estrutural, a capacidade contributiva pode ser definida como aptidão para suportar o ônus tributário, a capacidade de arcar com a despesa decorrente do pagamento de determinado tributo. Já sob o ângulo funcional, o princípo da capacidade contributiva opera como critério destinado a diferenciar as pessoas, de modo a fazer com que se possa identificar quem são os iguais, sob o aspecto do Direito Tributário, quem são os desiguais e em que medida se igualam, a fim de que se possa aplicar o princípio da igualdade com justo tratamento a cada um deles (CONTI, 1997, p. 24).

O conteúdo indeterminado da capacidade contributiva faz alguns doutrinadores, à exemplo de Alfredo Augusto Becker, não considerá-la como um princípio, mas majoritariamente se compreende que seu conteúdo indeterminado não é indeterminável.

Considerada um princípio devido a sua generalidade, abstração e carga axiologia, a capacidade contributiva é caracterizada como um princípio constitucional tributário, um subprincípio da isonomia - que no Direito Tributário se desdobra em outros subprincípios como o da generalidade, da isonomia tributária, na primeira acepção do princípio da capacidade contributiva, enquanto pressuposto ou fundamento do tributo; na segunda acepção da capacidade contributiva, enquanto critério que gradua e limita a tributação (OLIVEIRA, 1998, pag. 22-21).

Além de garantir direitos fundamentais e individuais como o direito à igualdade, à propriedade e à vedação do confisco, a capacidade contributiva orientar o legislador que ao criar os impostos se deve graduado-los considerando-se a situação particular de cada contribuinte, permitindo que assim seja realizada a justiça tributária ao não exigir imposto acima do suportável, conforme leciona Chimenti:

A análise conjunta dos princípios da capacidade contributiva e da dignidade da pessoa humana determina que o mínimo existencial para o bem-estar do ser humano deve ser excluído de tributação. A fim de dar eficácia ao princípio da capacidade contributiva, faculta-se à administração tributária, respeitados os direitos individuais e os termos da 
lei, identificar os rendimentos do contribuinte, seu patrimônio e suas atividades econômicas (CHIMENTI, 2010, p. 32).

Embora tenha sido uma arma dos capitalistas, que detectaram que as despesas precisariam ser proporcionais a situação econômica do contribuinte como instrumento para evitar a miséria, é de idealistas do Estado Social que parte as defesas mais enfáticas da necessidade de delimitar a carga tributária do contribuinte em observância a sua capacidade econômica, acreditam no potencial deste instrumento para contribuir com reduções significativas das disparidades econômicas e da dificuldade de ascensão social.

Para a doutrina italiana majoritária a capacidade contributiva é a capacidade de pagar impostos do contribuinte que equivale a soma da riqueza disponível, apenas depois de satisfeitas todas as necessidades elementares para a existência do contribuinte, podendo ser absorvida pelo Estado, sem que seja necessário reduzir o padrão de vida do mesmo e sem prejudicar as suas atividades econômicas (BALEEIRO, 2010, p. 1119).

A Constituição Federal de 1988, em vários artigos, limita ao legislador o caráter dos tributos a serem instituídos por meio das suas hipóteses de incidência, limitando-as a fazê-la em detrimento do patrimônio, dos rendimentos e da atividade econômica do contribuinte, mas não aufere a importância de se considerar também as despesas com as necessidades básicas para uma existência digna, como leciona o mestre Aliomar Baleeiro:

A capacidade econômica de contribuir para as despesas do Estado é aquela que se define após a dedução dos gastos necessários à aquisição, produção e manutenção da renda e do patrimônio, assim como do mínimo indispensável a uma existência digna para o contribuinte e sua família (...) o seu ferimento pelo tributo terá efeito confiscatório da renda ou do patrimônio (BALEEIRO, 2010, p. 867).

Segundo Baleeiro, a capacidade econômico-contributiva do contribuinte é aquela que se encontra após a dedução dos gastos necessários à aquisição, produção e manutenção da renda e do patrimônio. Tais considerações, com os caracteres que têm de pessoalidade e de graduabilidade, na medida da igualdade ou da desigualdade, só têm aplicação ampla nos impostos sobre a renda, o patrimônio e seus acréscimos (BALEEIRO, 2010, p. 863).

É um princípio explícito, cuja redação se encontra no art. 145 , § $1^{\circ}$, da Constituição Federal/88 e traz outros elementos para a discussão - os termos "sempre que possível” e “capacidade econômica”, vejamos:

(...)

$\S 1^{\circ}$ - Sempre que possível, os impostos terão caráter pessoal e serão graduados segundo a capacidade econômica do contribuinte, facultado à administração tributária, especialmente para conferir efetividade a esses objetivos, identificar, respeitados os direitos individuais e nos termos da lei, o patrimônio, os rendimentos e as atividades econômicas do contribuinte. 
Antes de se atribuir, ou não, capacidade contributiva à um cidadão, faz-se necessário, anteriormente verificar sua capacidade econômica. Um indivíduo pode ter condições de participar da economia do seu país enquanto consumidor, ou seja, possui capacidade econômica; mas pode não ter capacidade contributiva, pois consome toda a sua renda com a aquisição do mínimo existencial. Logo, a “capacidade contributiva pressupõe a econômica, mas não se confunde com ela” (DUTRA, 2010, pag. 28). A capacidade econômica é um critério de definição da capacidade contributiva, mas não o único.

Para Baleeiro a utilização da capacidade econômica é o critério mais importante e válido, pois através deste os seres podem ser enquadrados em uma categoria determinada. Por isso, a distinção, segundo a capacidade econômica, é imposta ao legislador de impostos, em acordo com a sua natureza jurídica específica (BALEEIRO, 2010, p. 1102).

O termo “sempre que possível” é considerado por doutrinadores como Paulo de Barros Carvalho dispensável, visto que uma norma jurídica não poderia trazer ao ordenamento jurídico elemento que seja impossível de ser cumprido. Para outros, como Baleeiro, trata-se de um termo indispensável, pois abrange as possibilidades de sua aplicação, não sendo uma cláusula permissiva, nem confere poder discricionário ao legislador, e sim acentua o grau de imperatividade e abrangência do dispositivo (BALEEIRO, 2010, p. 1097).

A questão reside, como bem aborda Hugo de Brito Machado, em saber qual a abrangência da expressão “sempre que possível”, utilizada no art. 145, § $1^{\text {o }}$, da CF/88, embora concorde que "nem sempre é possível dar a um imposto o caráter pessoal. A graduação segundo a capacidade econômica, todavia, é possível sempre, e não apenas em relação aos impostos pessoais” (MACHADO, 2004, p. 83).

José Maurício Conti defende que todos os impostos podem sujeitar-se ao princípio da capacidade contributivo-econômica, mesmo que sejam pessoais e não permitam uma aferição direta desse princípio. Pois, mesmo os tributos sem caráter pessoal, entre os quais incluem-se os que atingem a renda consumida, possuem mecanismos - como a seletividade, por exemplo - que tornam possível gravar mais pesadamente os indivíduos que exteriorizam uma capacidade contributiva mais elevada (MACHADO, 2012, p. 48).

Na matéria de tributos a Constituição brasileira visa proteger o cidadão de eventuais abusos do Estado através do princípio da capacidade contributiva, e seu conceito econômico e de justiça social. Ainda assim, existem alguns impostos que, devido à técnica de arrecadação 
utilizada, dificultam a aplicação deste princípio e acabam por estagnar uma sociedade em suas desigualdades.

O imposto de renda é um dos raros impostos que, através das alíquotas diferencias, consegue efetivar os princípios da igualdade e da capacidade contributiva, pois distribuem de forma proporcional os ônus de prover as necessidades da coletividade. Da mesma forma a isenção (forma de extrafiscalidade) para contribuintes com menor capacidade econômica ou para microempresas. Excessos nas isenções a empresas com elevados rendimentos e grandes patrimônios, porém, podem caracterizar violação do princípio da capacidade contributiva (CHIMENTI, 2010, p. 32).

Embora a Carta Magna determine que os impostos, sempre que possível, tenham caráter pessoal, no presente ordenamento, são exemplos de impossibilidade de aplicação do tributo seguindo o caráter pessoal os impostos que incidem sobre a importação, a produção ou a circulação de bens e serviços é o caso do Imposto sobre Produtos Industrializados - IPI e do Imposto sobre Circulação de Mercadorias e Serviços - ICMS. Esses impostos são indiretos, pois o sujeito passivo transfere a terceiros, o denominado consumidor final, os tributos que incidem sobre o produto ou serviço, são exceções não só do princípio da pessoalidade, mas também do da capacidade contributiva. Baseiam-se na seletividade da alíquota ou na isenção de gêneros de primeira necessidade.

\subsection{Proporcionalidade e progressividade}

Além das divergências sobre a expressão "sempre que possível”, o termo capacidade econômica, citada no mencionado artigo, é passível de profundas discussões. Misabel Abreu, em atualização da obra do grande jurista Aliomar Baleeiro, considera que a capacidade econômico-contributiva do contribuinte é aquela que se encontra após a dedução dos gastos necessários à aquisição, produção e manutenção da renda e do patrimônio; só sendo possível a aplicação da pessoalidade e graduabilidade, de maneira ampla, nos impostos sobre a renda, o patrimônio e seus acréscimos (BALEEIRO, 2010, p. 863).

Foi com esse intuito que os artigos 145, § $1^{\circ} ; 153$, $\S 2^{\circ}$, I e $\S 4^{\circ}$, I; 182, § $4^{\circ}$, II, todos da Constituição brasileira vigente, foram redigidos - fazer com que a tributação não atenue as grandes disparidades econômicas oriundas dos fatos, ao passo que veda a proporcionalidade e garante a progressividade e a igualdade: 
A progressividade nos tributos é a única técnica que permite a personalização dos impostos, como determina expressamente o art. 145, § $1^{\circ}$, da Constituição de 1988. É que a medida que o legislador considera as necessidades pessoais dos contribuintes, passa também a conceder reduções e isenções. Tais renúncias de receitas, ocorrentes em favor do princípio da igualdade, têm de ser compensadas por meio da progressividade a fim de que o montante da arrecadação se mantenha o mesmo no total (BALEEIRO, 2010, p. 1165).

Importante salientar que não há o que confundir entre a proporcionalidade e a progressividade. A proporcionalidade “(...) permite que mesmo com alíquota fixa o valor final de um tributo seja maior ou menor de acordo com o montante de sua base de cálculo, na progressividade a alíquota cresce à medida que a base de cálculo aumenta” (CHIMENTI, 2010, p. 35). O princípio da proporcionalidade encontra espaço no ordenamento jurídico de países orientados pelo liberalismo econômico onde incide o princípio “leave them as you find them”, denominada de teoria da equivalência, que mostra o caráter neutro do Estado, a mesma neutralidade do princípio da proporcionalidade; o que não condiz com os ideais e objetivos do Estado Social , não apenas do Brasil, mas também de países como a Alemanha, Itália e Espanha (BALEEIRO, 2010, p. 869-870).

$\mathrm{O}$ artigo $3^{\circ}$ da Constituição brasileira discorre sobre os objetivos fundamentais da República Federativa do Brasil: construir uma sociedade livre, justa e solidária; garantir o desenvolvimento nacional; erradicar a pobreza e a marginalização e reduzir as desigualdades sociais e regionais; e, promover o bem de todos, sem preconceitos de qualquer forma. A progressividade é fundamental para que sejam alcançados esses objetivos, no Direito Tributário, funciona como instrumento “à disposição do Estado (Democrático de Direito) para a construção de uma sociedade mais livre, justa e solidária” (BALEEIRO, 2010, p. 870).

Na proporcionalidade há “regressividade” ao invés de progressividade, isto ocorre, pois a alíquota desses impostos não observa a essencialidade e seletividade dos produtos. Ou seja, uma alíquota única onera pessoas com capacidade contributiva diversa, ricos e pobres, fazendo com que a carga tributária se torna insignificante para os que possuem renda maior e por demais onerosa para os pobres (CHIMENTI, 2010, p. 35).

A progressividade, do ponto de vista econômico, social ou jurídico, mostra-se indispensável não apenas para o cumprimento dos objetivos da República Federativa do Brasil, mas também para a obtenção da essência do princípio da igualdade. Sobre o sistema tributário italiano Biscaretti Di Ruffia coloca que a igualdade, quando entendida corretamente, impõe que aquele que goza de rendas mais elevadas deve contribuir aos gastos públicos com porcentagem progressivamente mais alta do que os que gozam de rendas baixas (RUFFIA Apud BALEEIRO, 2010, p. 870). 
O único caso previsto de progressividade claramente na Carta Magna é o relativo às alíquotas do Imposto sobre a Propriedade Predial e Territorial Urbana - IPTU e o Imposto sobre a Propriedade Territorial Rural - ITR; e, que até o ano de 2000 permitia a progressividade apenas quanto ao tempo subutilização ou não utilização e a produtividade, respectivamente. Quando da edição da Emenda Constitucional n. 29/2000, permitiu-se também que a progressividade do imposto que recai sobre a propriedade urbana e rural ocorresse também em função do valor, localização e uso do imóvel.

A Emenda de n. 29 é objeto de discussão quanto à constitucionalidade do seu texto, sob a alegação de ferir o princípio da capacidade contributiva por incidir a progressividade sobre um imposto real, indireto, motivada pelo valor do imóvel, para Chimenti o critério da progressividade do IPTU em razão do valor do imóvel "por si só, não é inconstitucional, mas deve a lei instituidora do critério cuidar para que a gradação do imposto reflita a capacidade contributiva do contribuinte” (CHIMENTI, 2010, p. 34). Ao contrário do que alega os defensores da inconstitucionalidade, a progressividade ao incidir sobre o valor do imóvel, que por si só reflete a capacidade contributiva do seu proprietário, faz com que tenhamos uma definição e se leve em consideração a capacidade econômica do mesmo.

\subsection{Capacidade econômica objetiva ou subjetiva}

Parte da doutrina divide a capacidade econômica nas modalidades objetiva-absoluta ou subjetiva-relativa, divisão defendida, principalmente, por Emilio Giardina. Do ponto de vista objetivo, o legislador ordinário é obrigado a somente instituir tributos cujo fato da hipótese de incidência contenha indícios de capacidade econômica, autorizar todas as despesas operacionais e financeiras necessárias a produção da renda e à conservação do patrimônio. O mesmo princípio impede que a lei permita o abatimento dos gastos destinados ao exercício do trabalho, da ocupação profissional como fonte, a origem dos rendimentos (BALEEIRO, 2010, p. 1096).

Do ponto de vista subjetivo, a capacidade econômica somente se inicia após a dedução das despesas necessárias para a manutenção de uma existência digna para o contribuinte e sua família (gastos pessoais obrigatórios como p. ex: alimentação, vestuário, moradia, saúde, dependentes, etc.). Corresponde a um conceito de renda ou patrimônio líquido e pessoal, livremente disponível para consumo e para o pagamento de tributo (BALEEIRO, 2010, p. 693).

O Brasil é um dos poucos exemplos, principalmente do mundo ocidental, que trás no seu texto constitucional a competência tributária atrelada às possíveis hipóteses de incidência. 
Essa rigidez que impede os legisladores municipais e estaduais de inventar novos impostos e o princípio da capacidade impedem uma miscigenação legal entre renda, rendimento e faturamento, o que faz com que parte da doutrina compreenda que o sistema tributário brasileiro adota a capacidade econômica objetiva. Nos demais países, a competência não gera entraves, o único entrave são os óbices constitucionais da tributação segundo a capacidade econômica (BALEEIRO, 2010, p. 1096).

A maneira que o sistema tributário e constitucional se configura, impede a incidência da capacidade econômica em todas as espécies de tributos. Mas a doutrina, num movimento cada vez maior que se iniciou na Itália, discute a utilização desses critérios em todas as espécies de tributos - impostos, taxas e contribuições. Iniciada nas últimas décadas, doutrinadores estrangeiros e nacionais dissentem em relação ao tema.

José Maurício Conti defende que todos os impostos podem sujeitar-se ao princípio da capacidade, pois, mesmo os tributos sem caráter pessoal, entre os quais incluem-se os que atingem a renda consumida, possuem mecanismos - como a seletividade, por exemplo - que tornam possível gravar mais pesadamente os indivíduos que exteriorizam uma capacidade contributiva mais elevada (CONTI, 1997, p. 48). Na mesma linha, Francesco Moschetti e Aliomar Baleeiro defendem a obrigatoriedade apenas aos impostos porque a base de cálculo destes contém indícios da capacidade econômica do contribuinte, são os chamados tributos não vinculados; enquanto que as taxas e contribuições direcionam a arrecadação a uma atuação estatal ou vantagem imobiliária, estes são os vinculados.

A corrente que defende a aplicação do princípio a todos os tributos tem como adeptos José Marcos Domingues de Oliveira, Ricardo Lobo Torres, Fernando Aurélio Zivelti, Gisele Lemke, Luciano Amaro, Edilson Pereira Nobre Júnior, Roberto Ferraz, Ricardo Lodi Ribeiro, Victor R. do Amaral Junior, Bernardo Ribeiro de Moraes, Sacha Calmon Navarro Coêlho, dentre outros.

Já Regina Helena Costa, Hugo de Brito Machado, Américo Lacombe, Vittorio Cassone, Adilson Rodrigues Pires, Yoshiaki Ichiahara, Roque Antonio Carrazza, Luiz Felipe Negrão, Ana Neyle Olímpio Holanda, dentre outros, defendem a aplicação da capacidade contributiva somente aos impostos.

A doutrina diverge quanto a aplicação desses critérios às diversas categorias de tributos, se o princípio em questão incide sobre todas as espécies de tributos, ou apenas sobre os impostos 
e contribuições; sua incidência sobre os impostos pessoais e reais, apenas sobre os pessoais, outra parte apenas sobre algumas modalidades de pessoais.

\section{CONCLUSÕES}

Um Sistema Tributário que tenha como pressuposto arrecadar o necessário para suprir as necessidades da população e assegurar a proteção dos seus direitos fundamentais, não apenas dos seus contribuintes, e que atente as diferenciações econômicas dos cidadãos é objeto de desejo de toda a sociedade. Um clamor diário proferido em todo o território nacional - chega inclusive a ultrapassar suas fronteiras -, vozes intensas e presentes nas diversas camadas da sociedade, demonstra o quão urgente e necessária se fazem reformulações.

Podemos citar o princípio da capacidade contributiva como um exemplo do quanto os problemas sociais acabam por impedir ditames constitucionais. Mas se aplicado corretamente, em conformidade com o princípio da igualdade, poderá contribuir para dirimir essa problemática de ordem social e econômica.

Ilustres palavras são utilizadas pelo mestre Aliomar Baleeiro para demonstrar a proporção da revolução social que a aplicabilidade da capacidade contributiva e dos seus subprincípios pode trazer:

Arma política de eficiência comprovada, o imposto pessoal e progressivo poderá ser o instrumento surdo e adequado a uma revolução social sem 'sangue, suor ou lágrimas’, mas, tão radical quanto as de caráter catastrófico que têm congestionado cemitérios, cárceres e orfanatos, apavorando as sociedades ameaçadas pela sua propagação insinuante e insidiosa (BALEEIRO, 2010, p. 1103).

Entretanto, a maioria dos brasileiros, que detém menor parcela das riquezas do país, paga alta carga tributária nos impostos embutidos nos produtos e nos demais que não respeitam a capacidade econômica do contribuinte nem a progressividade na sua tributação, ocorrendo o pagamento de tributos em excesso, inclusive em produtos da denominada cesta básica, cabendo séria e profunda reflexão, para se chegar a um patamar suportável e digno. O que acaba por estimular a sonegação de tributos, a economia informal e a insegurança jurídica, principalmente pelos menos favorecidos e articuladores da economia informal. O cidadão-contribuinte pode ser um grande aliado desse desenvolvimento, o problema está na forma que o Estado gasta o que é arrecadado - sobre este assunto, não adentraremos no presente estudo.

Assim, tanto no aspecto social como no econômico, a arrecadação de impostos no Brasil excede a capacidade contributiva da maioria dos cidadãos, que figuram o pólo passivo da relação tributária, e que não têm o retorno que deveriam ter do Estado. É necessário desenvolver 
simultaneamente o controle dos gastos públicos com a sua correta aplicação em prol da população, em especial da parcela menos favorecida socioeconomicamente, e a consciência fiscal do contribuinte.

Sabendo que o Estado apenas arrecadará o que necessita e aplicará o montante arrecado em prol da população, o contribuinte passará a ser um aliado do sistema tributário brasileiro, pois saberá que está contribuindo com o que lhe é possível e com o que o Estado necessita. Sua capacidade contributiva será respeitada em acordo com a sua capacidade econômica, consolidando, assim, o Estado Democrático de Direito e suas normas constitucionais que prezam pela igualdade e justiça social.

Dentre várias divergências, ficamos com a certeza de que tais elementos trazem ao ordenamento jurídico: segurança jurídica, abolição de privilégios, graduação de tributos de acordo com a capacidade contributiva, igualdade de oportunidades e redução das disparidades socioeconômicas e, consecutivamente, o desenvolvimento nacional. "Entretanto, o cumprimento dos ditames constitucionais esbarra exatamente no sentimento pernicioso dos exagerados contrastes” (BALEEIRO, 2010, p. 852).

A Carta Magna brasileira, o seu artigo $145, \S 1^{\circ}$, como já apresentado e comentado no presente estudo, traz o termo "sempre que possível”, não para limitar, mas para abranger as hipóteses a serem consideradas a pessoalidade.

\section{REFERÊNCIAS}

ARISTÓTELES. Política. 5a ed. Trad.: Pedro Constantin Tolens. São Paulo: Martin Claret, 2001.

BALEEIRO, Aliomar. Limitações constitucionais ao poder de tributar. $8^{\mathrm{a}}$ ed. Atualizada por Mizabel Abreu de Machado Derzi. Rio de Janeiro: Editora Forense, 2010.

Uma Introdução à Ciência das Finanças. 3ª ed. Rio de Janeiro: Forense, 2004.

BECKER, Alfredo Augusto. Teoria Geral do Direito Tributário. $2^{\mathrm{a}}$ ed. São Paulo: Saraiva, 1972.

CANOTILHO, Joaquim José Gomes. Direito Constitucional. $4^{\text {a }}$ ed. Coimbra: Almedina, 1986.

Direito Constitucional e Teoria da Constituição. $7^{\mathrm{a}}$ ed. Coimbra: Almedina, 2003. 
CARrAZZA, Roque Antonio. Curso de Direito Constitucional Tributário. $20^{\mathrm{a}}$ ed. São Paulo: Malheiros, 2004.

CARVALHO, Paulo de Barros. Curso de Direito Tributário. 18a ed. São Paulo: Saraiva, 2007.

CHIMENTI, Ricardo Cunha. Direito Tributário. 13ª ed. São Paulo: Saraiva, 2010.

CONSTITUIÇÃO da República Federativa do Brasil, de 05 de outubro de 1988. Brasília: Diário Oficial da União $\mathrm{n}^{0}$ 191, 1988. Disponível em <http://www.planalto.gov.br/ccivil_03/constituicao/douconstituicao88.pdf $>$

CONTI, José Maurício. Sistema Constitucional Tributário: Interpretado pelos Tribunais. São Paulo, Belo Horizonte: Oliveira Mendes/Del Rey, 1997.

. Princípios Tributários da Capacidade Contributiva e da Progressividade. São Paulo: Dialética: 1996.

DUTRA, Micaela Dominguez. Capacidade Contributiva: análise dos direitos humanos e fundamentais. São Paulo: Saraiva, 2010.

KELSEN, Hans. Teoria Geral do Direito e do Estado. São Paulo: Martins Fontes, 2000.

LIMA NETO, Manoel Cavalcante de. Direitos Fundamentais dos Contribuintes: Limitações Constitucionais ao Poder de Tributar. Recife: Nossa Livraria, 2005.

MACHADO, Hugo de Brito. Curso de Direito Constitucional Tributário. São Paulo: Malheiros, 2012.

. Os Princípios Jurídicos da Tributação na Constituição de 1988. $5^{\mathrm{a}}$ ed. São Paulo: Dialética, 2004.

MELLO, Celso Antonio Bandeira de. Conteúdo Jurídico do Princípio da Igualdade. $3^{\mathrm{a}}$ ed. São Paulo: Malheiros, 2007.

OLIVEIRA, José Marcos Domingues de. Capacidade Contributiva: conteúdo e eficácia do princípio. $2^{\mathrm{a}}$ ed. Rio de Janeiro: Renovar, 1998.

SILVA, José Afonso da. Curso de Direito Constitucional Positivo. 36a ed. São Paulo: Malheiros Editores, 2013. 